\title{
IbM (IPTEKS BAGI MASYARAKAT) POMPA HYDRAM (HYDRAULIC RAM) DESA GUNUNGRONGGO KECAMATAN TAJINAN KABUPATEN MALANG
}

\author{
Runi Asmaranto $^{1 *}$, Denny Widhiyanuriyawan ${ }^{2}$, M Ruslin Anwar $^{3}$ \\ ${ }^{1}$ Jurusan Teknik Pengairan Fakultas Teknik Universitas Brawijaya, ${ }^{2}$ Jurusan Teknik Mesin Fakultas Teknik \\ Universitas Brawijaya, ${ }^{3}$ Jurusan Teknik Sipil Fakultas Teknik Universitas Brawijaya \\ *runi_asmaranto@ub.ac.id
}

\begin{abstract}
ABSTRAK: Desa Gunungronggo terletak di Kecamatan Tajinan yang mana desa ini berjarak sekitar $15 \mathrm{KM}$ arah timur Kota Malang. Wilayah ini berada di lereng Gunung Buring, secara topografi didominasi oleh perbukitan dengan kelerengan yang curam dengan curah hujan yang relatif tinggi sehingga punya potensi sumber air yang cukup besar yaitu Sumber Jenon. Ketersediaan debit air Sumber Jenon cukup besar sekitar 300 liter/detik, namun belum menjamin penduduk Desa Gunungronggo khususnya Dusun Argomulyo 2 dan Argomulyo 3 untuk mendapatkan air bersih, meskipun secara geografis letaknya berdekatan dengan sumber. Selain itu lokasi sumber jauh dari jaringan utilitas listrik dan belum ada pengelola HIPPAM, sehingga hanya penduduk yang mampu secara ekonomi yang bisa mengambil air dengan menggunakan pompa secara individu dengan membentangkan kabel listrik cukup jauh dan membahayakan. Salah satu solusinya adalah membuat Pompa Hydram (hydraulic ram) agar murah dalam pelaksanaan operasi dan pemeliharaan. Kondisi masyarakat yang kurang mampu sangat sulit untuk mengembangkan pompa centrifugal atau lainnya yang mengandalkan bahan bakar solar maupun listrik. Kesadaran masyarakat untuk menanggung biaya operasi dan pemeliharaan yang lebih mahal akan sulit untuk mengembangkan pengelolaan air bersih, sehingga pompa hydram (hydraulic ram) ini menjadi solusi yang tepat.

Pompa hydram yang terbangun berjumlah 2 unit disebut sebagai twin hydram yang masing-masing berkapasitas@15 liter/menit, namun karena kondisi lokasi sumber yang cukup datar sehingga kinerja pompa hanya menghasilkan sekitar @10 liter/menit. Peningkatan kapasitas pompa bisa dilakukan dengan menambah pipa drainasi berukuran 4" sepanjang $100 \mathrm{~m}$ ke arah hilir untuk membuang dengan cepat limpahan air yang terbuang dari pompa hydram agar tidak mengganggu klep pompa yang terendam air. Kegiatan ini mendapatkan dukungan baik oleh warga maupun aparat desa, terbukti dalam pelaksanaannya beberapa pekerjaan dilakukan secara gotong-royong.
\end{abstract}

Kata Kunci : IbM, Hydraulic Ram, Katup Limbah, Pipa Drive, Pipa Delivery

ABSTRACT: The village of Gunungronggo is located in the Tajinan district where is about 15 kilometers east of Malang. The area is located on hillside of Buring, which in the topography of the village is dominated by hills with steep slopes with relatively high rainfall that has the potential sources of spring water and one of well maintained spring is Jenon Spring. The existence of spring discharge water at Jenon is large enough about 300 liters/sec, but not guarantee the residents in the village of Gunungronggo particularly both Argomulyo 2 and Argomulyo 3 to get fresh water from Jenon spring, although geographically adjacent. This conditions, it far from the utility of electricity and there is no HIPPAM (drinking water association), so that only people who are economically able to take up water using a pump individually by pulling the power cord.

One solution for the problems is built hydraulic ram pumps to fill water into the reservoir in order to reduce in the implementation of the Operation and Maintenance.Moreover of poor people is very hard to develop this type of centrifugal pump or other pumps that rely on diesel fuel and electricity. Public awareness to bear the costs of operation and maintenance that is expensive, will be difficult to develop water management, so development hydraulic ram pump became the appropriate solution.

Keywords: IbM, Hydraulic Ram, Waste Valves, Pipes Drive, Pipe Delivery 
Tubuh manusia terdiri dari 55\% sampai $78 \%$ air, tergantung dari ukuran badan. Agar dapat berfungsi dengan baik, tubuh manusia membutuhkan antara satu sampai tujuh liter air setiap hari untuk menghindari dehidrasi. Dari banyaknya volume air tawar yang ada dibumi, ternyata tidak semua air tawar baik dikonsumsi oleh manusia dan makhluk hidup karena adanya pencemaran dan perubahan fisik air. Sebelum terjadi pencemaran, kondisi air permukaan (air sungai, danau, waduk) masih cukup layak untuk dikonsumsi. Selain itu secara alamiah air permukaan masih mampu menetralisir dari berbagai muatan polutan yang merugikan bila dikonsumsi, seperti racun dan kotoran, sehingga tetap layak dikonsumsi namun dengan upaya pengolahan khusus. Sekarang ini, keberadaan air yang masih layak untuk dikonsumsi tinggal air tanah dan mata air (Asdak 2002).

Desa Gunungronggo terletak di Kecamatan Tajinan bejarak sekitar $15 \mathrm{KM}$ arah timur Kota Malang. Wilayah ini berada di lereng gunung buring, yangmana terdiri dari sekitar 1933 KK atau setara dengan 8000 jiwa (Anonim 2016). Secara topografi wilayah desa ini didominasi oleh perbukitan dengan kelerengan yang curam dengan curah hujan yang relatif tinggi sehingga punya potensi sumber air. Sumber air yang cukup besar dan terawat yaitu Sumber Jenon. Ketersediaan debit mata air Sumber Jenon cukup besar sekitar 300 liter/detik, namun belum menjamin penduduk Desa Gunungronggo untuk mendapatkan air bersih sekitar 9 liter/detik secara kontinu untuk pelayanan seluruh penduduk di Desa Gunung Ronggo Kecamatan Tajinan. Kondisi eksisting pengambilan/ pemanfaatan air dari Sumber Jenon oleh penduduk di Desa Gunung Ronggo Kecamatan Tajinan digambarkan sebagai berikut:

1. Sumber Jenon meskipun secara administrasi berada di wilayah Desa Gunungronggo, namun kurang bisa mengoptimalkan peman-faatan untuk kebutuhan air bersih karena elevasi mata air berada cukup jauh dibawah rumah penduduk.

2. Penduduk di 2 (dua) dusun yaitu dusun Argomulyo 2 dan Argomulyo 3 dengan jumlah total sekitar $500 \mathrm{KK}$ sementara ini mengambil air minum air secara individu (bagi yang mampu) dengan menarik kabel listrik cukup jauh melintasi ladang yang membahayakan warga lainnya. Selain itu pengambilan air dilakukan dari saluran irigasi hasil limpasan/outlet Sumber Jenon dimana hal ini masih jauh memadai dari aspek secara kualitas air.

3. Pengambilan air secara individu (belum terbentuk kelompok HimpunanPemakai Air Minum/HIPPAM), menyebabkan air minum belum dikelola dengan baik sehingga bisa menjamin ketersediaan air secara bijaksana menyangkut aspek hajat hidup orang banyak.

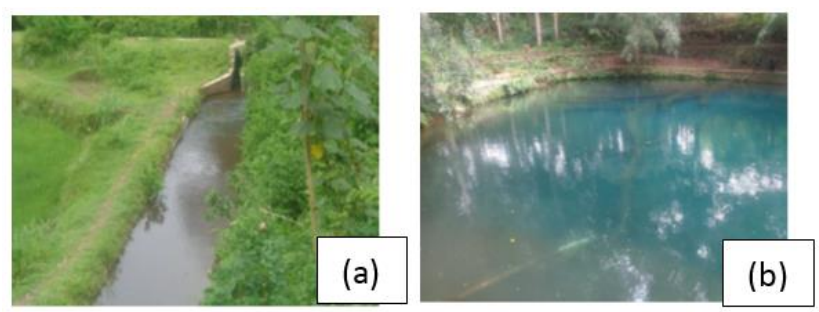

Gambar 1. (a) Saluran air irigasi terbuka yang dimanfaatkan untuk pengambilan air bersih

Dusun Argomulyo 2 dan Argomulyo 3. (b) Mata Air Sumber Jenon.

\section{KAJIAN PUSTAKA}

Pompa hydram diperkenalkan sebagai salah satu dari serangkaian teknologi energi renewable air pedesaan. Pompa hydram yang memanfaatkan penghentian aliran secara tibatiba didalam pipa untuk membuat gelombang tekanan tinggi, hal ini umumnya dikenal sebagai pukulan air (water hammer). Gelombang tekanan tinggi ini yang dimanfaatkan untuk memompa air (Schiller, EJ, 1982). Menurut Schiller, dalam sejarahnya pompa hydram hadir lebih dari 200 tahun yang lalu diamana diawali oleh krisis bahan bakar fosil dan kekurangan energi pada umumnya. Hydram hadir bersama dengan teknologi energi terbarukan lainnya seperti kincir angin, handpumps dan perangkat surya. Orang pertama yang mencoba menggunakan tekanan pukulan air dalam pipa untuk memompa adalah John Whitehurst, seorang Inggris pada tahun 1775 . Namun pompa hydramnya belum otomatis, operasinya saat itu masih dikendalikan secara manual dengan membuka dan menutup katup stop-cock sehingga waktu itu menjadi kurang populer.

Penemu hydram otomatis seperti yang kita kenal sekarang adalah seorang Prancis, Joseph Montgolfier, yang dipatenkan pada tahun 1797. Dia mengenalkan katup limbah yang dibuka dan ditutup secara otomatis dan diberi nama pompa hydraulic ram. 


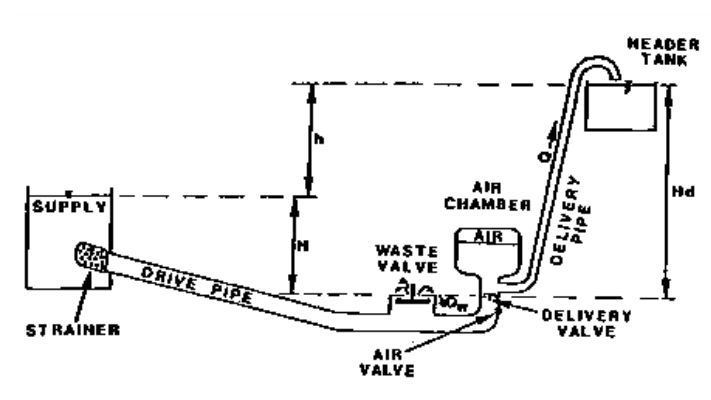

Gambar 2. Susunan umum instalasi hydram (Calhoun, 2003)

Pompa hydram cukup sederhana dalam konstruksi. Hanya berisi dua bagian yang bergerak, katup limbah (waste valve) dan katup pengiriman (delivery valve). Ada dua pipa; pipa drive mendorong air menuju ke dalam pompa dan pipa pengiriman mengarahkan air ke tempat di mana ia akan disimpan dan kemudian digunakan. Sebuah ruang udara dan katup udara adalah dua komponen lainnya di dalam tubuh hydram tersebut.

Siklus pemompaan dari hydram dimulai dengan katup limbah terbuka. Dalam aliran alami, pasokan diambil dari hulu, bisa dari bendungan kecil yang dibuat di sungai. Head mempercepat air dalam pipa drive dan melewati katup buang. Persamaan untuk percepatan ini dikenal dalam mekanika fluida diberikan sebagai berikut:

$H-M \frac{v^{2}}{2 g}=\frac{L}{g} \frac{d v}{d t}$

dengan : $\mathrm{M} \mathrm{v}^{2} / 2 \mathrm{~g}=$ kehilangan akibat gesekan

$\mathrm{L}=$ panjang pipa dorong (drive pipe)

$\mathrm{v}=$ kecepatan air dalam pipa

$\mathrm{t}=$ waktu

Kemudian aliran akan cukup mempercepat untuk mulai menutup katup limbah. Hal ini terjadi ketika hambatan dan kekuatan tekanan di dalam air sama dengan berat katup limbah. Gaya pada katup dapat direpresentasikan sebagai kekuatan tarik (drag forced) $\mathrm{Fd}$, yang diberikan oleh persamaan berikut :

$F_{d}=C_{d} A_{v} \gamma \frac{v^{2}}{2 g}$

dengan ;

$\mathrm{A}_{\mathrm{v}} \quad=$ luas penampang katup limbah

$\gamma \quad=$ berat jenis air

$\mathrm{C}_{\mathrm{d}} \quad=$ koefisien seret dari katup limbah

Untuk pengoperasian optimal,

penutupan katup harus secepat mungkin. Atas dasar ini katup dengan panjang stroke yang pendek biasanya akan didapatkan hasil yang terbaik. Namun, jika katup terlalu ringan, katup tidak akan membuka segera saat siklus pompa bekerja; di sisi lain jika stroke terlalu pendek, tidak cukup air bisa lepas dari pembukaan katup buang, hal ini membatasi kecepatan pipa dan dengan demikian mengurangi tekanan pukulan air. Diperlukan desain yang tepat dari katup limbah karena itu harus ada keseimbangan optimal antara berbagai faktor yang terlibat dalam siklus pompa.

Penutupan tiba-tiba katup limbah menciptakan gelombang tekanan tinggi seperti yang dijelaskan sebelumnya. Lonjakan ini cukup besar untuk membuka katup pengiriman (drive valve) dan melepaskan beberapa air ke dalam pipa pengiriman. Dengan pelepasan air ini, kenaikan tekanan didalam pipa dorong berkurang dan sedikit terjadi tekanan negatif.

Tiga hal yang signifikan terjadi ketika gelombang tekanan runtuh pada pipa drive. Pertama, katup pengiriman menutup dan mengakhiri lonjakan tekanan yang dikirimkan ke pipa pengiriman. Ruang bantalan udara tertekan sehingga terdapat cukup aliran untuk dikirim ke pipa outlet/pengiriman. Dalam proses redaman oleh bantalan ini muka udaraair terus bereaksi dan bergerak. Hal ini cenderung melarutkan udara ke dalam air, kemudian pasokan udara diisi kembali oleh fenomena kedua yang terjadi pada tahapan tersebut. Akibat tekanan negatif memungkinkan udara untuk tersedot ke dalam katup udara.

Tahap ketiga adalah terjadi pada akhir fase tekanan pemompaan yaitu dengan terbukanya katup buang, baik oleh aksi beratnya sendiri atau melalui sebuah aliran air yang aktiv, ketika ini terjadi aliran air siap untuk memulai siklus lagi. Siklus hydram demikian berulang terus menerus, pada frekuensi antara 40-200 pukulan per menit. Fakta bahwa pompa hydram ini beroperasi selama 24 jam per hari dengan hanya perawatan minimal adalah merupakan salah satu keuntungan utama.

Efisiensi pompa hydram sering dirumuskan sebagai berikut :

$e=\frac{Q . h}{Q w . H}$

dengan;

$\mathrm{Q} / \mathrm{Q}_{\mathrm{w}}=$ rasio debit

$\mathrm{h} / \mathrm{H}=$ rasio head 


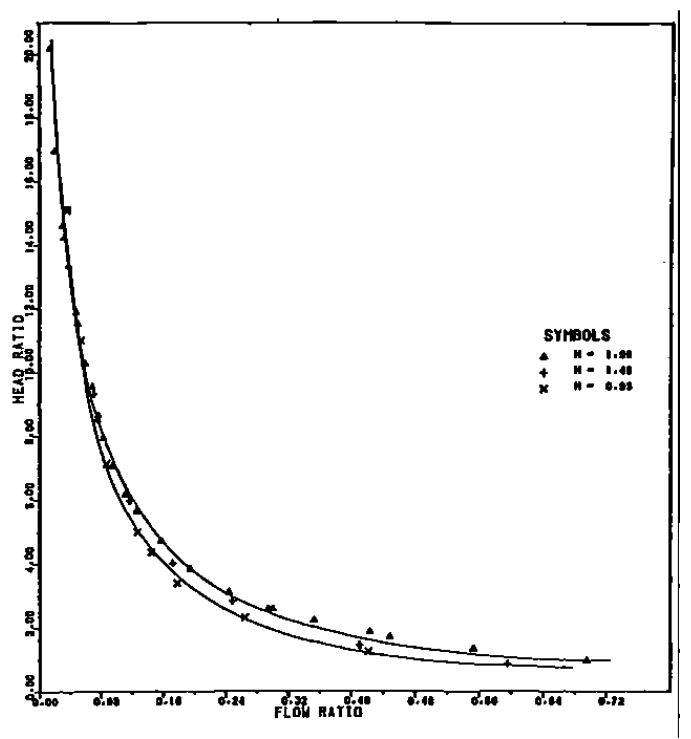

Gambar 3. Grafik hubungan antara rasio Head $(\mathrm{h} / \mathrm{H})$ dengan rasio aliran $\left(\mathrm{Q} / \mathrm{Q}_{\mathrm{w}}\right)$

\section{BAHAN DAN METODE}

Metode yang digunakan dalam program pengabdian masyarakat IbM ini adalah melakukan perencanaan dan pembangunan pompa hydram untuk mengatasi kekurangan air bersih yang dipompa dari sumber Jenon. Pemanfaatan Pompa hydram menggunakan teknologi tepat guna yang mudah diaplikasikan di lapangan dan bisa dilakukan transfer of technology kepada masyarakat mitra. Sesuai dengan prioritas masalah yang telah dirumuskan maka beberapa kegiatan dirancang dalam kegiatan IbM ini untuk menyelesaikan permasalahan yang ada. Beberapa kegiatan tersebut adalah :

1. Desain pompa hydram, yang meliputi desain jaringan air bersih dan kebutuhan pompa hydram, spesifikasi pompa, debit inlet dan outlet, dimensi pipa pendorong dan pembawa, head, dll

2. Pembangunan pompa hydram, yang meliputi pembangunan pompa hydram yang sesuai dengan kebutuhan masyarakat di Argomulyo2 dan 3 untuk mengisi tandon air.

3. Pelatihan operasi dan pemeliharaan pompa hydram yang nantinya akan diserahkan kepada masyarakat untuk di kelola dikoordinir oleh Kepala Desa.

Luaran kegiatan ini dilokasi mitra akan direncanakan pemasangan 2 buah pompa hydram kembar dengan kapasitas yang sama yang terhubung dalam satu buah pipa delivery, selanjutnya di sebut dengan istilah twin hydram.
Tabel. 1. Karakteristik Pompa Hydram Gunung Ronggo

\begin{tabular}{|c|c|c|}
\hline No & Parameter & Dimensi \\
\hline 1 & $\mathrm{H}$ & $1,5 \mathrm{~m}$ \\
\hline 2 & $\mathrm{H}$ & $10 \mathrm{~m}$ \\
\hline 3 & $\mathrm{Hd}$ & $11,5 \mathrm{~m}$ \\
\hline 4. & Diameter Pipa drive & 2 inchi $(5 \mathrm{~cm})$ \\
\hline 5 & $\begin{array}{l}\text { Diameter Pipa } \\
\text { delivery }\end{array}$ & 1 inchi $(2,5 \mathrm{~cm})$ \\
\hline 6 & Panjang Pipa drive & $60 \mathrm{~m} \times 2$ pompa \\
\hline 7 & $\begin{array}{l}\text { Panjang pipa ke } \\
\text { tandon }\end{array}$ & $200 \mathrm{~m}$ \\
\hline 8 & $\begin{array}{l}\text { Kebutuhan Air } \\
\text { Penduduk }\end{array}$ & 40 liter/orang/hari \\
\hline 9 & Debit masuk Qw & 1,331 liter/detik \\
\hline 10 & $\begin{array}{l}\text { Debit keluaran Q (1 } \\
\text { bh pompa) }\end{array}$ & 5 liter/menit \\
\hline 11 & $\begin{array}{l}\text { Debit Keluaran Q (2 } \\
\text { bh pompa) }\end{array}$ & 10 liter/menit \\
\hline 12 & $\begin{array}{l}\text { Jumlah Penduduk } \\
\text { Terlayani }\end{array}$ & 360 jiwa \\
\hline 13 & Efisiensi pompa & $41,7 \%$ \\
\hline
\end{tabular}

Sumber: hasil perencanaan

\section{HASIL DAN PEMBAHASAN}

Tahapan awal desain prototype

Setelah dilakukan tahapan survei identifikasi di lapangan, maka diketahui bahwa beda tinggi antara Sumber Jenon ke rencana tandon sekitar $10 \mathrm{~m}$, sedangkan kendala dilapangan adalah minimnya head untuk pipa dorong mengingat lokasi disekitar sumber relatif datar. Alternatif solusinya adalah menggali pondasi pompa agar diperoleh head yang agak besar sekitar 1,5 meter. Sedangkan jarak (L) dari sumber ke rumah pompa adalah 60 meter atau membutuhkan 10 batang pipa besi 2" masing-masing panjang @6 meter, sehingga untuk 2 buah pompa hydram (twin hydram) adalah total 20 batang pipa besi. Untuk body pump digunakan pipa besi berukuran 4" dan tabung udara (chamber) juga digunakan pipa 4".
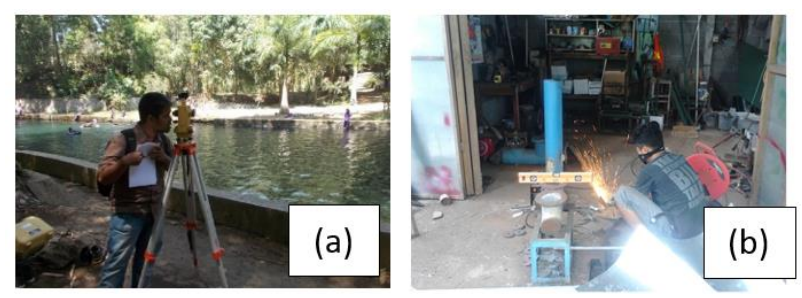

Gambar 4. (a) Kegiatan pengukuran elevasi pada tahap awal desain dan (b) pembuatan prototype pompa. 
Setelah semua kegiatan pembuatan prototype selesai, maka selanjutnya adalah penentuan trase pipa, survei pemilikan lahan dan koordinasi dengan perangkat desa khususnya terkait dengan penggunaan lahan. Dari hasil diskusi dan survei lapangan didapatkan jalur-jalur trase pipa delivery dan transmisi serta lokasi pondasi pompa yang sesuai dengan kriteria teknis dan keinginan warga.
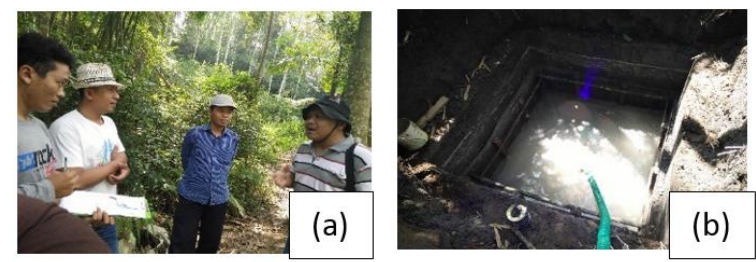

Gambar 5. (a) diskusi lapangan penentuan lokasi pompa dan trase pipa. (b) penggalian pondasi pompa .

Pada saat pelaksanaan lapangan yaitu kegiatan penggalian pondasi pompa, ditemukan berbagai masalah teknis yaitu banyak rembesan mengalir di ruang galian sehingga proses galian dan pengecoran pondasi mengalami kesulitan serta membutuhkan waktu yang lebih lama dari rencana (Gambar 5 b). Untuk mengatasi hal ini maka dilakukan dewatering atau penurunan muka air tanah dengan pompa sentrifugal untuk membantu proses pelaksanaan penggalian. Selain itu pengecoran dinding tembok penahan rumah pompa dilakukan dengan penambahan bahan lapisan kedap air (impermeable) agar rembesan berkurang. Namun upaya ini belum menghasilkan solusi yang optimal, sehingga perlu dibuat saluran drainasi dari pondasi pompa ke arah hilir sejauh 100 meter agar air rembesan segera teralirkan secara gravitasi. Perlu diketahui bahwa penggalian pondasi pipa sedalam 1,5 meter dilakukan untuk meningkatkan head (h) dari sumber ke pompa.

\section{Setting Pompa}

Setting pompa dilakukan untuk mengatur katup limbah maupun katup delivery sehingga akan diperoleh debit yang optimal. Parameter yang menentukan terhadap debit pengeluaran adalah jarak katup yang mempengaruhi volume air yang terbuang dan terdorong ke tandon. Selain itu pengaturan katup juga mempengaruhi jumlah tumbukan air (water hammer).
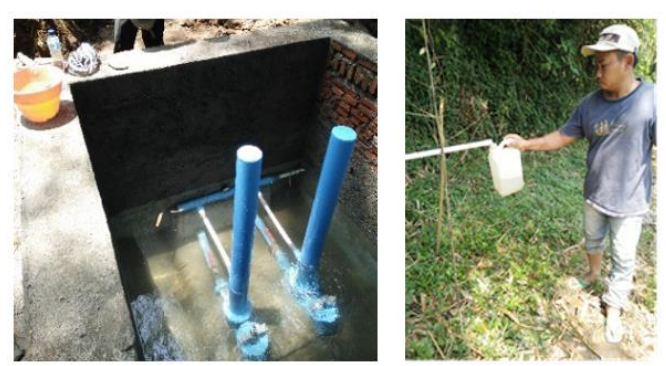

Gambar 6. Setting Pompa dan pengukuran debit output

Hasil pengaturan katup limbah diperoleh jarak sekitar $3 \mathrm{~cm}$ yang paling optimal menghasilkan debit 10 liter/menit. Nilai ini sangat dipengaruhi juga oleh berat katup limbah yang ditentukan oleh jenis bahan yang digunakan. Pada kondisi normal, seharusnya kinerja twin hydram tersebut mampu menghasilkan debit 30 liter/menit. Penurunan debit ini disebabkan kondisi katup limbah terendam air sisa buangan water hammer dimana air limbah seharusnya segera keluar mengalir meninggalkan rumah pompa. Namun karena kondisi kontur di lokasi yang relatif datar, hal ini sulit dilakukan secara almiah (mengalir gravitasi) karena pondasi digali sedalam 1,5 meter untuk mendapatkan head drive minimal $=1,5$ meter. Solusi yang mungkin bisa dilakukan adalah menambah pipa drainasi minimal 4 inchi dengan menyambung sepanjang 100 meter ke arah hilir yang lebih rendah sehingga air sisa buangan pada katup limbah dapat segera keluar dan tidak menyebabkan aliran tenggelam pada sistem pompa. Dari hasil pengukuran dan perhitungan diperoleh nilai efisiensi pompa (e) sebagai berikut:

$\mathrm{e}=\frac{Q \cdot h}{Q w \cdot H}=\frac{\frac{10 l i t e r}{m e n i t} \cdot 10 \mathrm{~m}}{1,33 \frac{\text { liter }}{\text { menit }} \cdot 1,5}=41 \%$

\section{KESIMPULAN}

Dari hasi pelaksanaan kegiatan Ibm (Ipteks bagi Masyarakat) Pompa Hydram Desa Gunung Ronggo ini maka bisa diberikan kesimpulan sebagai berikut :

1. Kegiatan pengabdian kepada masyarakat dapat memberikan kontribusi yang sangat besar bagi masyarakat mitra, untuk pencapaian kehidupan yang layak terutama penyediaan utilitas air bersih. 
2. Kegiatan ini mendapatkan respon yang sangat baik oleh semua pihak khususnya masyarakat mitra dan diharapkan keberlanjutan pengelolaan pompa hydram dapat dilakukan secara mandiri untuk diserahkan dan dikelola oleh kelompok HIPPAM masyarakat setempat.

3. Debit pompa twin hydram sekarang ini menghasilkan debit output 10 liter/menit dan dapat ditingkatkan maksimal 30 liter/menit dengan melakukan beberapa pekerjaan fisik tambahan yang bisa dikerjakan secara swadaya masyarakat dengan memasang saluran drainasi pipa 4 “ sepanjang 100 meter ke arah hilir secara gravitasi untuk menghindari aliran tenggelam pada katup limbah.

4. Efisiensi kerja pompa twin hydram sebesar $41 \%$ artinya debit sebesar $59 \%$ terbuang melalui katup limbah dan kembali ke saluran irigasi.

5. Satu keunggulan pompa twin hydram di Gunung Ronggo ini adalah kerja pompa selama 24 jam tiada henti dengan tanpa menggunakan bahan bakar atau sumber energi listrik. Sedangkan biaya operasi dan pemeliharaan cukup murah yaitu perbaikan klep atau katup limbah (waste valve)

\section{UCAPAN TERIMA KASIH}

Ucapan terima kasih disampaikan kepada semua pihak yang telah membantu kegiatan pengabdian kepada masyarakat ini, khususnya kepada Direktorat Penelitian dan Pengabdian kepada Masyarakat, Direktorat Jenderal Pembelajaran dan Kemahasiswaan Kementerian Riset Teknologi dan Pendidikan Tinggi Program Direktorat Penelitian dan Pengabdian kepada Masyarakat. Selain itu juga disampaikan terima kasih kepada Lembaga Penelitian dan Pengabdian Kepada Masyarakat Universitas Brawijaya (LPPM UB), Badan
Penelitian dan Pengabdian Kepada Masyarakat (BPPM) FT UB serta masyarakat Desa Gunung Ronggo khususnya Dusun Argomulyo.

\section{DAFTAR PUSTAKA}

Anonim, 2016. Kabupaten Malang dalam Angka. BPS Kabupaten Malang

Asdak, Chay. 2002. Hidrologi dan Pengelolaan Daerah Aliran Sungai. Yogyakarta. Gadjah Mada University Press.

Calhoun, John 2003. Home Built Hydrauilc Ram Pumps. NW Independent Power Resources PO BOX 899

Hanafie, J., de Long, H., 1979, Teknologi Pompa Hidraulik Ram., Pusat Teknologi Pembangunan Institut Teknologi Bandung, Bandung

Petunjuk Teknis Departemen Pekerjaan Umum, 2002, Pemanfaatan Pompa Hydram Dalam Penyediaan Air Bersih, Petunjuk Teknis Nomor: Pt-T11-2002-C

San, G.S, Santoso, G., 2002, Studi Karakteristik Volume Tabung Udara dan BebanKatup Limbah Terhadap Efisiensi Pompa Hydraulic Ram, Jurnal Teknik Mesin,Vol. 4. No. 2, Jurusan Teknik Mesin, Fakultas Teknologi Industri, UniversitasKristen Petra.

Schiller, E.J. (1982) "Development of a Locally Made Hydraulic Ram Pump". ENERGEX '82 Conference Proceedings, Solar Energy Society of Canada. August, pp. 503-506.

Taye, T., 1998. Hydraulic Ram Pump, Journal of the ESME, Vol II, No.1 (http://www.africantechnologyforum. org/ESME/hydram1/Hydram1.htm) 